\title{
Optimal Fare, Vacancy Rate, and Subsidies under Log-Linear Demand with the Consideration of Externalities for a Cruising Taxi Market
}

\author{
Chun-Hsiao Chu \\ Department of Tourism, Aletheia University, New Taipei City 25103, Taiwan \\ Correspondence should be addressed to Chun-Hsiao Chu; shawchu@mail.au.edu.tw
}

Received 25 June 2016; Accepted 5 December 2016; Published 15 January 2017

Academic Editor: Chaudry M. Khalique

Copyright (c) 2017 Chun-Hsiao Chu. This is an open access article distributed under the Creative Commons Attribution License, which permits unrestricted use, distribution, and reproduction in any medium, provided the original work is properly cited.

Externality is an important issue for formulating the regulation policy of a taxi market. However, this issue is rarely taken into account in the current policy-making process, and it has not been adequately explored in prior research. This study extends the model proposed by Chang and Chu in 2009 with the aim of exploring the effect of externality on the optimization of the regulation policy of a cruising taxi market. A closed-form solution for optimizing the fare, vacancy rate, and subsidy of the market is derived. The results show that when the externality of taxi trips is taken into consideration, the optimal vacancy rate should be lower and the subsidy should be higher than they are under current conditions where externality is not considered. The results of the sensitivity analysis on the occupied and vacant distance indicate that the relation of the vacant distance to the marginal external cost is more sensitive than the occupied distance. The result of the sensitivity analysis on the subsidy shows the existence of a negative relationship between the marginal external cost and the optimal subsidy.

\section{Introduction}

The taxi is a mode of paratransit in the urban public transit system. It is a popular mode of transportation in urban areas because of its embedded features of convenience, speediness, privacy, comfort, long hours of operation, and door-to-door delivery with no need to pay parking fees. If the fare of a taxi service is reasonable and the quality is good enough, using the service of taxis is attractive to private vehicle users. This may also result in a reduction in the external cost incurred by using private vehicles (e.g., environmental pollution, congestion, and fuel consumption) and enhance the efficiency and safety of the transportation system in urban areas.

A cruising taxi means a taxi that is continually driving about looking for business. When a client is found, the taxi is defined as having business. Although intelligent dispatching is now being used in the taxi business, the drivers of vacant taxis still cruise the streets to find business opportunities. Cruising taxis always exist and are perhaps the most basic mode of operation in the taxi industry.
Due to the characteristics of taxi operation, taxi trips have both positive and negative external effects. When a taxi is occupied by passengers, it may create positive external effect because it reduces the use of private vehicles and the external cost incurred. However, when a cruising taxi carries no passengers, it may cause the same negative external effects as a private vehicle. Externality in the taxi market is an important issue which is worth noting and being researched. However, it is often overlooked by authorities and researchers alike.

As a kind of public transportation system, the taxi business is often regulated and supervised by public authorities in most cities around the world. The regulation policies include quantity (considering the vacant and occupied distance in the market), fare, and subsidy/taxation. Ideally, the externality of the taxi business should be taken into account when the regulation policy is being discussed by the authorities because, if not considered, the most effective allocation of public resources may not be achieved.

In the studies related to taxi regulation, the log-linear demand function has often been specified to describe the 
market demand of taxi trips because this specification has the advantages of allowing the demand elasticity to be obtained directly from the formula and its parameters are very easily calibrated. However, the common restriction of the conventional log-linear demand function is that the price elasticity has to be restricted to be less than -1 . Hence, Chang and $\mathrm{Chu}$ [1] introduced the concept of "maximum social willingness-to-pay (MSWTP)" to deal with the restriction. However, in their model, the concept of externality, which is an important but often overlooked by authorities and researchers issue, was not taken into account.

In this study an extended model based on Chang and Chu's one is proposed and solved to analyze the effect of externality on the optimization of the fare, vacancy rate, and subsidy of the taxi cruising market in the first-best environment where taxi trips need to be subsidized [2].

\section{Literature Review}

The taxi industry is highly regulated. The regulation policies include quantity, fare, and subsidy/taxation. Hence, the optimization of vacancy rate, fare, and subsidies is an important issue in the policy-making process.

In 1972, Douglas [3] proposed an abstract model to explore the effect of different fares and characteristics of equilibrium for the cruising taxi market. In Douglas's study, demand is a function of fare and service quality, which is evaluated by the users' waiting time. Ghahraman et al. [4] discussed a time- and space-based fare structure for the taxi industry. Ardekani et al. [5] suggested that certain factors need to be considered in the establishment of fare structure such as fuel cost, driver salary, operation costs, and reasonable profit. Chang and $\mathrm{Tu}$ [6] proposed a time-based fare scheme that took 12 cost factors into account in the cost-sharing procedure. They also divided the 12 cost factors into 3 different types, namely, fixed cost, variable cost, and mixed cost, in accordance with their correlations to travel time and distance. Chang and Sun [7] proposed a concept for a flexible initial fare and suggested that the authorities set a range so that the taxi operators can flexibly adjust the initial fare to reflect changing demands. To realize the concept of the flexible initial fare, Chang and Chu [8] further developed a discrete dynamic control model and solved the problem of optimal control rate of the initial fare to match with the changing demand and maintain the vacancy rate on a predetermined level.

Some have suggested that the taxi industry should be subsidized. Teal and Berglund [9] argued that subsidizing a taxi-pool may be an alternative for the taxi industry in the US. Arnott [2] suggested that taxi travel should be subsidized and that the subsidy should cover the shadow cost of taxi idle time in the first-best environment. Frankena and Pautler [10] reviewed the regulation policies for four taxicab market segments (namely, cruising cabs, cabs that wait at stands, radio-dispatched cabs, and cabs that provide contract services) and discussed market imperfections including externalities of congestion and pollution that might occur in the taxicab service market. Their study showed that some imperfections indeed provide theoretical rationale for regulation of the cruising taxicab market. However, they also admit that economists have not developed a model of the cruising cab segment that determines a unique equilibrium fare and service combination.

To regulate the number of taxis in the market is also an important area of concern. Some studies have focused on this subject area. Beesley and Glaister [11] considered that the taxi demand is a function of fare and waiting time and discussed the variation of taxi demand and waiting time when the taxi fare is changed. Schaller [12] studied the elasticity of price and the service availability by using econometric methods. Wong and Yang [13], Yang and Wong [14], Wong et al. [15], and Yang et al. [16] developed a series of taxi optimization models using mathematical programming methods based on the O-D matrix and the network of the service area. By materializing Douglas' research, Chang and Huang [17] proposed an optimal vacancy rate and fare model to maximize the social welfare for a cruising taxi market with a break-even constraint. However, under Chang and Huang's model, the consumers' surplus would not exist when the price elasticity is greater than -1 . To deal with the problem of inexistence of the consumer's surplus in Chang and Huang's model, Chang and Chu [1] further introduced the concept of "maximum social willingness-to-pay (MSWTP)" and obtained the optimum of fare, vacancy rate, and subsidy for cases in which the absolute value of price elasticity is less than 1 .

Based on the above, it can be found that the issue of externality of the vacancy rate, fare, and subsidy of the taxi industry has rarely been presented in the prior research related to the optimization of taxi regulation. As a type of public transportation, the taxi business could cause positive and/or negative external effects on social welfare. This study thus aims at exploring the effect of externality on the optimization of vacancy rate, fare, and subsidy of the taxi industry and attempts to develop a model accordingly.

\section{Analytical Model}

An analytical model based on the model proposed by Chang and Chu in 2009 is discussed in this section for the optimization of the fare, vacancy rate, and subsidy with the consideration of externality.

A review of previous research is carried out first. The externality function of the cruising taxi industry derived in this study will also be discussed. We then derive and solve the optimization problem for the fare, vacancy rate, and subsidy with the consideration of externality.

3.1. Models in Previous Studies. In 1972, Douglas presented an abstract model for a cruising taxi market and gave an example with a log-linear delay (waiting time) function.

In Douglas' study, the demand was assumed to be a function of the fare and waiting time. The demand of the taxi market can be written as

$$
Q=f(P, w),
$$


where $Q$ is the total demand of the taxi market, $P$ is the taxi fare, $T$ is the waiting time of the taxi, and $\partial f / \partial P<$ $0, \partial f / \partial w<0$.

Further, the waiting time is a function of the density of vacant taxis and can be expressed as

$$
w=g(V)
$$

where $V$ is the density of vacant taxis.

Regarding the supply, Douglas assumed the supply of taxicabs and drivers to be perfectly elastic, given as a cost per unit taxi service, $c$. It is also assumed that the cost of operating cruising taxicabs is independent of the division of operation time between "vacant" and "occupied." Hence, the total cost can be given by

$$
T C=c(Q+V) .
$$

Under these settings, equilibrium occurs at

$$
P\left[\frac{Q}{Q+V}\right]=c
$$

or

$$
P Q=c(Q+V) .
$$

By materializing Douglas' research, Chang and Huang [17] proposed an optimum vacancy rate and fare model that maximized the social welfare for a cruising market with the break-even constraint. Chang and Huang's study follows the setting of cost structure and the relationship between the density of vacant taxis $(V)$ and the waiting time $(w)$ in Douglas' research and specified a log-linear function as the demand function.

In Chang and Huang's study, the demand function was expressed as

$$
\begin{aligned}
& Q=A_{1} P^{\alpha_{1}} w^{\beta_{1}}, \quad \alpha_{1}<0, \beta_{1}<0 \\
& w=A_{2} V^{\alpha_{2}}, \quad \alpha_{2}<0 \Longrightarrow \\
& Q=A_{1} P^{\alpha_{1}}\left(A_{2} V^{\alpha_{2}}\right)^{\beta_{1}} \Longrightarrow \\
& P=\left(\frac{Q}{A_{1} A_{2}^{\beta_{1}} V^{\alpha_{2} \beta_{1}}}\right)^{1 / \alpha_{1}},
\end{aligned}
$$

where $Q$ is daily occupied mileage in the market ( $\mathrm{km} /$ day), $V$ is total daily vacancy mileage $(\mathrm{km} /$ day), $P$ is fare rate of taxis (dollars/taxi-day), $w$ is waiting time of taxi passengers, $\alpha_{1}$ is price elasticity of taxi demand, $\alpha_{2}$ is vacant mileage elasticity of waiting time, $\beta_{1}$ is waiting time elasticity of taxi demand, $A_{1}$ is constant term of the demand function, and $A_{2}$ is constant term of the waiting time function.

Given Chang and Huang's settings, the consumer surplus (CS) is yielded as follows:

$$
\begin{aligned}
\mathrm{CS} & =\int_{0}^{\mathrm{Q}} P(X) d X-P Q \\
& =\int_{0}^{\mathrm{Q}}\left(\frac{X}{A_{1} A_{2}^{\beta_{1}} V^{\alpha_{2} \beta_{1}}}\right)^{1 / \alpha_{1}} d X-P Q \\
& = \begin{cases}\left(\frac{1}{A_{1} A_{2}^{\beta_{1}} V^{\alpha_{2} \beta_{1}}}\right)^{1 / \alpha_{1}}\left[\left.\frac{X^{1 / \alpha_{1}+1}}{1 / \alpha_{1}+1}\right|_{0} ^{Q}\right]-P Q, & \text { if } \alpha_{1} \neq-1 \\
\left(\frac{1}{A_{1} A_{2}^{\beta_{1}} V^{\alpha_{2} \beta_{1}}}\right)^{1 / \alpha_{1}}\left[\left.\ln x\right|_{0} ^{Q}\right]-P Q, & \text { if } \alpha_{1}=-1\end{cases} \\
& = \begin{cases}\left\{\frac{1}{\left(\frac{1 / \alpha_{1}}{A_{1} A_{2}^{\beta_{1}} V^{\alpha_{2} \beta_{1}}}\right)^{1 / \alpha_{1}+1}} \frac{Q^{1 / \alpha_{1}+1}-P Q,}{\text { if } \alpha_{1}<-1}\right. \\
\text { diverge, } & \text { if } 0 \geq \alpha_{1}>-1 \\
\text { diverge, } & \text { if } \alpha_{1}=-1 .\end{cases}
\end{aligned}
$$

Equation (10) shows that the consumers' surplus does not exist when the price elasticity $\left(\alpha_{1}\right)$ lies within the closed interval of $[0,-1]$ under the log-linear demand since CS is an improper integral and $X=0$ is its improper point.

To deal with the problem of the nonexistent consumer surplus, Chang and $\mathrm{Chu}$ further introduced the concept of the "maximum social willingness-to-pay" [1]. By the introduction of the "maximum social willingness-to-pay," the improper point from the CS could be shifted to become a negative point. The concept of the "maximum social willingness-to-pay" can be briefly explained as follows.

Assume that $P(q)$ is a demand function that satisfies

$$
P(q)=A q^{1 / \alpha}, \quad \alpha<0
$$




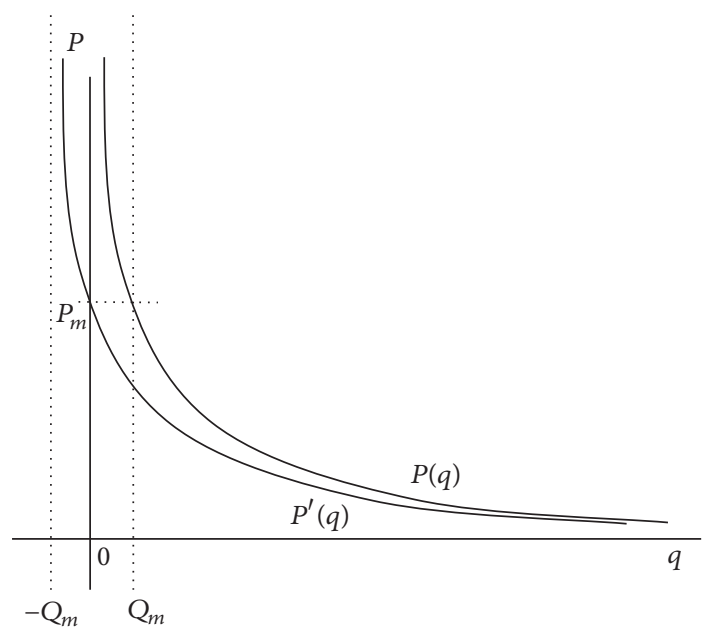

FIGURE 1: Illustration of the introduction of the maximum social willingness-to-pay.

$$
\lim _{a \rightarrow 0^{+}} \int_{a}^{X} p(q) d q=\infty
$$

Equation (11) shows that $P(q)$ is a conventional loglinear demand function whose price elasticity is $\alpha$ and (12) means that $\int_{a}^{X} p(q) d q$ is a divergent improper integral with an improper point $q=a$.

Equation (12) is an improper integral since the maximum willingness-to-pay is not considered in (11). Hence, it is assumed that there exists a maximum social willingness-topay $\left(P_{m}\right)$ so that $q=0$ if $P>P_{m}$ and that the shape of the demand is fixed. Geometrically, the introducing of the maximum social willingness-to-pay means the demand curve shifts to the left, say $P^{\prime}(q)$, as shown in Figure 1.

Here $Q_{m}$ means the shift distance between $P(q)$ and $P^{\prime}(q)$ which can be calculated as follows:

$$
\begin{aligned}
\because P_{m} & =P\left(Q_{m}\right)=A Q_{m}{ }^{1 / \alpha} \Longrightarrow \\
Q_{m} & =A^{-\alpha} P_{m}{ }^{\alpha} .
\end{aligned}
$$

In Figure 1, it is obvious that the social welfare and consumers' surplus under $P^{\prime}(q)$ are always less than those under $P(q)$. This implies that social welfare and consumers' surplus may be overestimated under the log-linear demand function due to the lack of consideration towards the maximum social willingness-to-pay. Furthermore, by shifting the demand curve from $P(q)$ to $P^{\prime}(q)$, the improper point will be shifted from $q=0$ to $q=-Q_{m}$. This means that the consumers' surplus and social welfare can be calculated when $\alpha_{1}$ lies within the interval of $(0,-\infty)$.
Additionally, $P^{\prime}(q)$ is a horizontal shift of $P(q)$; hence,

$$
\begin{aligned}
\int_{a-Q_{m}}^{x} p^{\prime}(q) d q & =\int_{a}^{x+Q_{m}} p(q) d q \Longrightarrow \\
\frac{d}{d x} \int_{a-Q_{m}}^{x} p^{\prime}(q) d q & =\frac{d}{d x} \int_{a}^{x+Q_{m}} p(q) d q \Longrightarrow \\
p^{\prime}(x) & =p\left(x+Q_{m}\right) .
\end{aligned}
$$

Therefore, when the occupied mileage for the taxi market increases from 0 to $O$ after considering the maximum social willingness-to-pay, the social welfare $(W)$ can be expressed as

$$
\begin{aligned}
W & =\int_{0}^{O} p^{\prime}(x) d x-T C(X) \\
& =\int_{0}^{O} p\left(x+Q_{m}\right) d x-T C(X), \quad \text { let } y=x+Q_{m} \\
& =\int_{Q_{m}}^{O+Q_{m}} p(y) d y-T C(X),
\end{aligned}
$$$$
\text { let } Q=O+Q_{m} \Longrightarrow
$$$$
W=\int_{Q_{m}}^{Q} p(y) d y-T C\left(Q-Q_{m}\right),
$$

where $O$ means the occupied mileages under the consideration of the maximum social willingness-to-pay.

Equation (19) indicates that it is not necessary for analyzers to change the integrand $P(q)$ when they are intending to calculate the social welfare under $P^{\prime}(q)$. What they need to do is merely change the lower bound of the integral of $P(q)$ and substitute $\left(Q-Q_{m}\right)$ into the total cost function.

Furthermore, because $O$ is also a shift of $Q$, the optimum occupied mileage $\left(Q^{*}\right)$ should be shifted a distance of $Q_{m}$ to obtain the welfare-maximized occupied mileage under $P^{\prime}(q)$.

In Chang and Huang's study, the demand function is

$$
Q=A_{1} P^{\alpha_{1}}\left(A_{2} V^{\alpha_{2}}\right)^{\beta_{1}}
$$

By substituting the maximum social willingness-to-pay $\left(P_{m}\right)$ into the demand function, we have

$$
Q_{m}=A_{1} P_{m}^{\alpha_{1}}\left(A_{2} V^{\alpha_{2}}\right)^{\beta_{1}}
$$

By shifting $Q$ to $\left(Q-Q_{m}\right)$, the relationship between $Q$ and $O$ can be obtained as follows:

$$
\begin{aligned}
\because O & =Q-Q_{m} \\
& =A_{1} P^{\alpha_{1}}\left(A_{2} V^{\alpha_{2}}\right)^{\beta_{1}}-A_{1} P_{m}^{\alpha_{1}}\left(A_{2} V^{\alpha_{2}}\right)^{\beta_{1}} \\
& =A_{1} P^{\alpha_{1}}\left(A_{2} V^{\alpha_{2}}\right)^{\beta_{1}}\left(1-\left(\frac{P_{m}}{P}\right)^{\alpha_{1}}\right) \Longrightarrow \\
O & =Q\left(1-\left(\frac{P_{m}}{P}\right)^{\alpha_{1}}\right) .
\end{aligned}
$$


3.2. Externality Function in the Taxi Industry. The externality function for the cruising taxi industry is characterized based on the marginal external costs of a private vehicle trip.

Assuming that the marginal external cost per unit distance of a private highway vehicle trip is $e$, the average number of passengers of a taxi trip is $L$. Furthermore, assuming that passengers do not want to use the taxi service for any reason, then the probability of them switching their use to private vehicles is $\pi$. Based on the above assumptions, when a taxi is occupied, the taxi trip may transfer $\pi \times L$ trips from private vehicles. Hence, if the daily occupied distance of the taxi market is $O$, the daily external benefit of a cruising taxi market $\left(e_{b}\right)$ can be expressed as

$$
e_{b}(O)=e \pi L O
$$

where $e$ is the marginal external cost per unit distance of a private highway vehicle passenger trip, $\pi$ is the probability of passengers switching their use to private vehicles when they do not want to use the taxi service, $L$ is the average number of passengers for a taxi trip, and $O$ is the daily occupied distance for the taxi market.

By assuming that the marginal external cost of a taxi trip is $k$ times the marginal external cost of a private highway vehicle trip, the marginal external cost of a taxi passenger trip would be $e k$. If daily operation distance (which includes the occupied and vacant distance) of the cruising taxi market is $(O+V)$, the daily external cost of the market $\left(e_{c}\right)$ is

$$
e_{c}(O, V)=e k(O+V)
$$

where $k$ is the marginal external cost multiplier of a taxi trip and $V$ is the daily vacant distance of the market.

Equations (24) and (25) reflect the fact that whether it is vacant or occupied, a taxi incurs external cost whenever it is being operated; however, a taxi may have external benefit due to the switching effect when it is occupied. Hence, the net daily external cost of the cruising taxi market can be obtained by simply taking the difference between (24) and (25). Thus, the net daily external cost for the cruising taxi market $\left(e_{N C}\right)$ can be written as

$$
\begin{aligned}
e_{N C}(O, V) & =e k(O+V)-e \pi L O \\
& =e(k-\pi L) O+e k V \\
& =e[(k-\pi L) O+k V] .
\end{aligned}
$$

The first term in (27) means that the net marginal external cost is $e(k-\pi L)$ when a taxi is occupied, whereas the second term means that the net marginal external cost is $e k$ when a taxi is vacant.

A negative net daily external cost for the cruising taxi market $\left(e_{N C}\right)$ implies the cruising taxi market carries a net external benefit. The condition can be obtained as follows:

$$
\begin{aligned}
e_{N C}(O, V) & =e \times[(k-\pi L) O+k V]<0 \Longrightarrow \\
e \pi L O & >e k(O+V) \Longrightarrow \\
1-R & =\frac{O}{O+V}>\frac{e k}{e \pi L}=\frac{k}{\pi L} \Longrightarrow \\
R & =\frac{V}{O+V}<1-\frac{e k}{e \pi L}=\frac{\pi L-k}{\pi L} .
\end{aligned}
$$

Equations (30) and (31) describe the condition where the cruising taxi market has a net external benefit. Equation (30) implies that if the distance occupied rate $(1-R)$ of a taxi market is greater than the ratio of marginal external cost to marginal external benefit of its occupied distance, the cruising taxi market would then have net external benefit. Alternatively, (31) implies that the cruising taxi market has a net external benefit if the distance vacancy rate $(R)$ is less than the ratio of net external benefit to gross net external benefit for its occupied distance.

3.3. Optimal Fare and Optimal Vacancy Rate. When the external cost is considered, the total social cost is simply the sum of the private cost and external cost. Hence, by extending Chang and Chu's model and considering the net external cost function, the welfare function $\left(W_{e}\right)$ can be written as

$$
\begin{aligned}
& W_{e}=\int_{Q_{m}}^{Q}\left(\frac{y}{A_{1} A_{2}^{\beta_{1}} V^{\alpha_{2} \beta_{1}}}\right)^{1 / \alpha_{1}} d y-T C\left(Q-Q_{m}\right)-e_{N C}\left(Q-Q_{m}, V\right) \\
& =\int_{A_{1} P_{m}^{\alpha_{1}}\left(A_{2} V^{\alpha_{2}}\right)^{\beta_{1}}}^{Q}\left(\frac{y}{A_{1} A_{2}^{\beta_{1}} V^{\alpha_{2} \beta_{1}}}\right)^{1 / \alpha_{1}} d y-c\left(Q-Q_{m}+V\right)-e\left((k-\pi L)\left(Q-Q_{m}\right)+k V\right) \\
& = \begin{cases}\frac{Q^{1 / \alpha_{1}+1} /\left(A_{1} A_{2}^{\beta_{1}} V^{\alpha_{2} \beta_{1}}\right)^{1 / \alpha_{1}}-A_{1} A_{2}^{\beta_{1}} V^{\alpha_{2} \beta_{1}} P_{m}^{1+\alpha_{1}}}{1 / \alpha_{1}+1}-c\left(Q-Q_{m}+V\right)-e\left((k-\pi L)\left(Q-Q_{m}\right)+k V\right), & \text { if } \alpha_{1} \neq-1, \alpha_{1} \neq 0 \\
A_{1} A_{2}^{\beta_{1}} V^{\alpha_{2} \beta_{1}}\left[\ln (Q)-\ln \left(\frac{A_{1}\left(A_{2} V^{\alpha_{2}}\right)^{\beta_{1}}}{P_{m}}\right)\right]-c\left(Q-Q_{m}+V\right)-e\left((k-\pi L)\left(Q-Q_{m}\right)+k V\right), & \text { if } \alpha_{1}=-1\end{cases} \\
& = \begin{cases}\frac{Q^{1 / \alpha_{1}+1} /\left(A_{1} A_{2}^{\beta_{1}} V^{\alpha_{2} \beta_{1}}\right)^{1 / \alpha_{1}}-A_{1} A_{2}^{\beta_{1}} V^{\alpha_{2} \beta_{1}} P_{m}^{1+\alpha_{1}}}{1 / \alpha_{1}+1}-c\left(Q-Q_{m}+V\right)-e\left((k-\pi L)\left(Q-Q_{m}\right)+k V\right), & \text { if } \alpha_{1} \neq-1, \alpha_{1} \neq 0 \\
A_{1} A_{2}^{\beta_{1}} V^{\alpha_{2} \beta_{1}}\left[\ln (Q)-\ln \left(\frac{A_{1}\left(A_{2} V^{\alpha_{2}}\right)^{\beta_{1}}}{P_{m}}\right)\right]-c\left(Q-Q_{m}+V\right)-e\left((k-\pi L)\left(Q-Q_{m}\right)+k V\right), & \text { if } \alpha_{1}=-1\end{cases}
\end{aligned}
$$




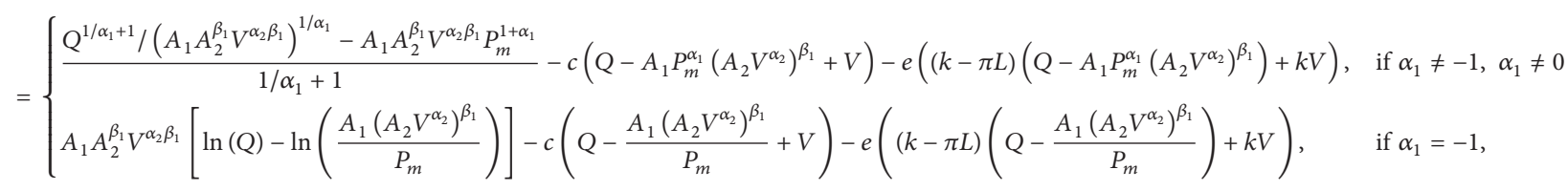

where $P_{m}$ is maximal social willingness-to-pay (MSWTP), $V$ is total daily vacant distance, $Q$ is total daily occupied distance in the market while $P_{m}$ equals $\infty, Q_{m}$ is minimal daily occupied distance when the taxi fare equals $P_{m}, c$ is marginal opportunity cost of operating a taxicab, $\alpha_{1}$ is price elasticity of taxi demand, $\alpha_{2}$ is vacant distance elasticity of waiting time, $\beta_{1}$ is waiting time elasticity of taxi demand, $A_{1}$ is constant term of the demand function, and $A_{2}$ is constant term of the waiting time function.

Chang and Chu proved that the welfare function with no external cost being considered is concave [1]. Since a linear external cost function is ineffective when applied to the concavity of the original function, the welfare function with the external cost is also concave. Hence, the welfare function has a unique optimal solution.

Equations (33) shows that the social welfare function has different shapes when $\alpha_{1}=-1$ and $\alpha_{1} \neq-1$ and $\alpha_{1} \neq 0$. Hence, the optimal solution should be discussed separately under different circumstances.
Case 1 (when $\alpha_{1} \neq-1$ and $\alpha_{1} \neq 0$ ). The first-order conditions (FOC) with respect to $Q$ and $V$ under $\alpha_{1} \neq-1$ can be written as

$$
\begin{aligned}
& \frac{\partial W_{e}}{\partial Q}=\left(\frac{Q}{A_{1} A_{2}^{\beta_{1}} V^{\alpha_{2} \beta_{1}}}\right)^{1 / \alpha_{1}}-(c-e(\pi L-k))=0 \\
& \frac{\partial W_{e}}{\partial V}=\alpha_{2} \beta_{1}\left(A_{1} A_{2}^{\beta_{1}}\right)^{-1 / \alpha_{1}} \\
& \quad \cdot V^{-\alpha_{2} \beta_{1} / \alpha_{1}-1} Q^{1 / \alpha_{1}+1}\left(\frac{-1}{1+\alpha_{1}}\right) \\
& \quad+\alpha_{2} \beta_{1} A_{1} A_{2}^{\beta_{1}} V^{\alpha_{2} \beta_{1}-1} P_{m}^{\alpha_{1}}\left(c-e \pi L+e k-\frac{P_{m} \alpha_{1}}{1+\alpha_{1}}\right) \\
& \quad-(c+e k)=0 .
\end{aligned}
$$

By solving the first-order condition and second-order condition and letting

$$
T_{e}=\frac{\left(P_{m} /(c-e(\pi L-k))\right)^{\alpha_{1}}\left(1+\alpha_{1}\left(1-P_{m} /(c-e(\pi L-k))\right)\right)-1}{1+\alpha_{1}}
$$

the optimal solution can be obtained:

$$
\begin{aligned}
& V^{*}=A_{1}^{1 /\left(1-\alpha_{2} \beta_{1}\right)} A_{2}^{\beta_{1} /\left(1-\alpha_{2} \beta_{1}\right)}(c-e(\pi L-k))^{\left(1+\alpha_{1}\right) /\left(1-\alpha_{2} \beta_{1}\right)}\left(\frac{\alpha_{2} \beta_{1} T_{e}}{c+e k}\right)^{1 /\left(1-\alpha_{2} \beta_{1}\right)} \\
& Q^{*}=A_{1}^{1 /\left(1-\alpha_{2} \beta_{1}\right)} A_{2}^{\beta_{1} /\left(1-\alpha_{2} \beta_{1}\right)}(c-e(\pi L-k))^{\left(\alpha_{1}+\alpha_{2} \beta_{1}\right) /\left(1-\alpha_{2} \beta_{1}\right)}\left(\frac{\alpha_{2} \beta_{1} T_{e}}{c+e k}\right)^{\alpha_{2} \beta_{1} /\left(1-\alpha_{2} \beta_{1}\right)} \\
& O^{*}=Q^{*}-Q_{m}\left(V^{*}\right) \\
& =A_{1}^{1 /\left(1-\alpha_{2} \beta_{1}\right)} A_{2}^{\beta_{1} /\left(1-\alpha_{2} \beta_{1}\right)}(c-e(\pi L-k))^{\left(\alpha_{1}+\alpha_{2} \beta_{1}\right) /\left(1-\alpha_{2} \beta_{1}\right)}\left(\frac{\alpha_{2} \beta_{1} T_{e}}{c+e k}\right)^{\alpha_{2} \beta_{1} /\left(1-\alpha_{2} \beta_{1}\right)}\left(1-\left(\frac{P_{m}}{c-e(\pi L-k)}\right)^{\alpha_{1}}\right) \\
& R^{*}=\frac{V^{*}}{V^{*}+O^{*}}=\frac{1}{\left(1+(c+e k) / \alpha_{2} \beta_{1} T_{e}(c-e(\pi L-k))\right)\left(\left(1-\left(P_{m} /(c-e(\pi L-k))\right)^{\alpha_{1}}\right)\right)} \\
& P^{*}=\left(\frac{O^{*}}{A_{1}\left(A_{2} V^{*}\right)^{\alpha_{2} \beta_{1}}}+P_{m}{ }^{\alpha_{1}}\right)^{1 / \alpha_{1}}=c-e(\pi L-k) \text {. }
\end{aligned}
$$

It is provable that $T_{e}$ is always positive and reaches its minimum value, 0 , when $P_{m}=c-e(\pi L-k)$. Moreover, Chang and Huang indicated that, for a taxi market which is in stable equilibrium, the condition that $0<\alpha_{2} \beta_{1}<1$ should be satisfied [17]. Hence, for a taxi market in stable equilibrium, $V^{*}, Q^{*}, O^{*}$, and $R^{*}$ can certainly have positive and real solutions.
Case $2\left(\alpha_{1}=-1\right)$. When $\alpha_{1}=-1$, the FOC with respect to $Q$ and $V$ can be written as

$$
\begin{aligned}
& \frac{\partial W}{\partial Q}=\frac{A_{1} A_{2}^{\beta_{1}} V^{\alpha_{2} \beta_{1}}}{Q}-(c-e(\pi L-k))=0 \\
& \frac{\partial W}{\partial V}=\alpha_{2} \beta_{1} A_{1} A_{2}^{\beta_{1}} V^{\alpha_{2} \beta_{1}-1}\left(\ln \frac{Q P_{m}}{A_{1} A_{2}^{\beta_{1}} V^{\alpha_{2} \beta_{1}}}\right.
\end{aligned}
$$




$$
\left.+\frac{c-e(\pi L-k)}{P_{m}}-1\right)-(c+e k)=0 .
$$

Similarly, by solving the first-order condition and secondorder condition, the optimum solution can be obtained as follows:

$$
\begin{aligned}
V^{*} & =\left(\frac{A_{1} \alpha_{2} \beta_{1} U_{e}}{c+e k}\right)^{1 /\left(1-\alpha_{2} \beta_{1}\right)} A_{2}^{\beta_{1} /\left(1-\alpha_{2} \beta_{1}\right)} \\
Q^{*} & =A_{1}^{1 /\left(1-\alpha_{2} \beta_{1}\right)} A_{2}^{\beta_{1} /\left(1-\alpha_{2} \beta_{1}\right)}\left(\frac{\alpha_{2} \beta_{1} U_{e}}{c+e k}\right)^{\alpha_{2} \beta_{1} /\left(1-\alpha_{2} \beta_{1}\right)} \frac{1}{c-e(\pi L-k)} \\
O^{*} & =Q^{*}-Q_{m}\left(V^{*}\right) \\
& =A_{1}^{1 /\left(1-\alpha_{2} \beta_{1}\right)} A_{2}^{\beta_{1} /\left(1-\alpha_{2} \beta_{1}\right)}\left(\frac{\alpha_{2} \beta_{1} U_{e}}{c+e k}\right)^{\alpha_{2} \beta_{1} /\left(1-\alpha_{2} \beta_{1}\right)} \frac{P_{m}-c+e(\pi L-k)}{P_{m}(c-e(\pi L-k))} \\
P^{*} & =\left(\frac{O^{*}}{\left.A_{1}\left(A_{2} V^{*}\right)^{\alpha_{2} \beta_{1}}+P_{m}^{\alpha_{1}}\right)^{1 / \alpha_{1}}}=c-e(\pi L-k)\right. \\
R^{*} & =\frac{V^{*}}{V^{*}+O^{*}}=\frac{1}{1+(c+e k) / \alpha_{2} \beta_{1} U_{e}(c-e(\pi L-k))\left(1-(c-e(\pi L-k)) / P_{m}\right)} \\
& =\frac{\alpha_{2} \beta_{1} U_{e} P_{m}(c-e(\pi L-k))}{\alpha_{2} \beta_{1} U_{e} P_{m}(c-e(\pi L-k))+(c+e k)\left(P_{m}-c+e(\pi L-k)\right)},
\end{aligned}
$$

where $U_{e}=\ln \left(P_{m} /(c-e(\pi L-k))\right)+(c-e(\pi L-k)) / P_{m}-1$.

Thus $U_{e}$ is always positive and its minimum value is 0 which occurs when $P_{m}=c-e(\pi L-k)$. Hence, a cruising taxi market with stable equilibrium can surely have positive and real solutions for $V^{*}, Q^{*}, O^{*}$, and $R^{*}$ as well as $P^{*}$.
3.4. The Optimal Subsidy. Although the marginal cost pricing is the optimal pricing in our model, it will cause a loss for the taxi operators, because vacant distance is unavoidable in the cruising taxi market. Hence, to shift the equilibrium, the authorities should subsidize the difference between the optimal fare $\left(P^{*}\right)$ and the average cost $(\mathrm{AC})$. Thus, the optimal lump-sum subsidy rate per occupied distance $\left(S_{e}{ }^{*}\right)$ should be

$$
\begin{aligned}
S_{e}^{*} & =\operatorname{AC}\left(O^{*}, V^{*}\right)-P^{*} \\
& =c\left(1+\frac{V^{*}}{O^{*}}\right)-P^{*} \\
& =\frac{c}{1-R^{*}}-P^{*} \\
& = \begin{cases}\frac{C}{1+\alpha_{2} \beta_{1} T_{e} P^{*} /(c+e k)\left(1-\left(p_{m} / P^{*}\right)^{\alpha_{1}}\right)}-P^{*}, & \text { if } \alpha_{1} \neq-1, \alpha_{1} \neq 0 \\
\frac{C}{1+\alpha_{2} \beta_{1} U_{e} P^{*} /(c+e k)\left(1-P^{*} / P_{m}\right)}-P^{*}, & \text { if } \alpha_{1}=-1 .\end{cases}
\end{aligned}
$$

Furthermore, a negative subsidy rate means the taxi business should be taxed. From (53), the condition for taxing can be obtained as follows:

$$
\begin{aligned}
& P^{*}=c-e(\pi L-k)>\frac{c}{1-R^{*}} \Longrightarrow \\
& \pi L<k-\frac{c R^{*}}{e\left(1-R^{*}\right)}=k-\frac{c V^{*}}{e O^{*}} \Longrightarrow
\end{aligned}
$$

$$
e(k-\pi L) O^{*}>c V^{*}
$$

The left side of (56) is the external cost of the occupied distance, whereas the right side is the vacant distance cost. Equation (56) shows that when the marginal external cost of the occupied distance is too high or the cost for switching to private vehicles is too low, the external cost of the occupied 


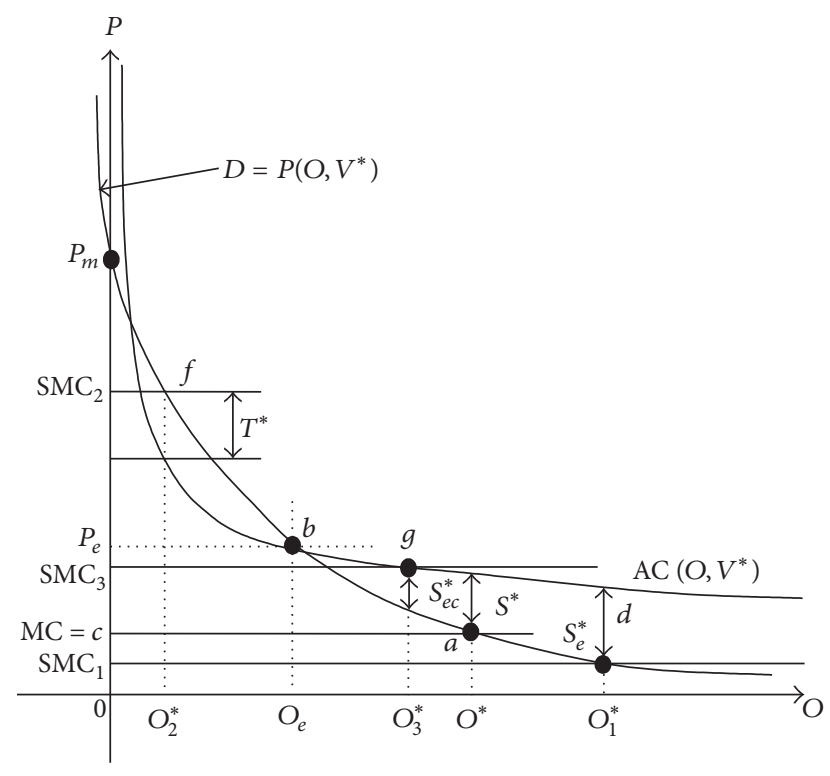

FIGURE 2: The relationship between demand function, average cost, marginal cost, and subsidy/taxation.

distance will be greater than that of the vacant distance; therefore, the taxi trip should be taxed.

Figure 2 shows a graphical explanation of the relationship between demand function, average cost, marginal cost, and subsidy/taxation when $V=V^{*}$. In the figure, the optimal fare and occupied distance, without consideration of externality, are $\left(c, O^{*}\right)$, that is, point $a$, and the natural point of equilibrium is $b$, while the equilibrium fare and occupied distance are $\left(P_{e}, O_{e}\right)$. Since AC is always higher than the marginal cost $(P=c)$, the pricing of the marginal will always cause a loss for the taxi operators due to vacant distance $\left(V^{*}\right)$. Hence, without the consideration of externality, if the policy-makers of the taxi industry want to shift equilibrium from point $b$ to point $a$ by offering a lump-sum subsidy to taxi operators to cover their idle time loss, the proper lump-sum subsidy should be $S^{*}$.

Now, with the consideration of externality, the social marginal cost (SMC) equals the marginal opportunity cost (c) plus the net external cost for the occupied distance, that is, SMC $=c+e(k-\pi L)=P^{*}$. When the net external cost is negative, which means a net external benefit is induced for the occupied distance of a taxi trip, and the social marginal cost $\left(\mathrm{SMC}_{1}\right)$ is lower than the marginal opportunity cost of the taxi $(c)$, then trips should be subsidized, the optimal fare should be $\mathrm{SMC}_{1}$, the optimal occupied distance should be $\mathrm{O}_{1}^{*}$, and the optimal subsidy rate should be $S_{e}^{*}$.

Let us consider another condition where the net external cost is positive, a net external cost is induced for the occupied distance of a taxi trip for the market, and the social marginal cost $\left(\mathrm{SMC}_{2}\right)$ is higher than the marginal cost of the taxi $(c)$. In this situation, taxi trips should be taxed, the optimal fare should be $\mathrm{SMC}_{1}$, the optimal occupied mileage should be $O_{1}^{*}$, and the optimal tax rate should be $T^{*}$.

In the last case where the net external cost is positive, a net external cost is incurred for the occupied distance of a taxi trip for the market but the social marginal cost $\left(\mathrm{SMC}_{3}\right)$ is still lower than the break-even fare $\left(P_{e}\right)$. In this situation, taxi trips should still be subsidized, the optimal fare should be equal to $\mathrm{SMC}_{3}$, the optimal occupied mileage should be $\mathrm{O}_{3}^{*}$, and the optimal subsidy rate should be $S_{e c}^{*}$.

\section{Numerical Analysis}

In the previous sections, the function of externality was formulated and a more generalized model based on Chang and Chu's study was also derived. To compare the differences between the solutions with and without the consideration of externality and between those from prior studies and this study, the parameter values used in the prior studies $[1,17]$ are applied.

4.1. Numerical Optimization Results. Although most of the parameters are based on the settings used in prior studies, the sources of some important parameters, which are used in the externality function, need to be explained. In terms of the marginal external cost (e), Chu [18] estimated the marginal external cost for private vehicles in Taiwan by introducing the Green National Income (GNI). According to Chu's estimation, the subjective and objective marginal external costs of a private vehicle trip are 1.768 and 0.2779 NTD ( 1 NTD $\fallingdotseq 0.03$ USD) per passenger per km. To briefly analyze the sensitivity of this parameter, both the subjective and objective marginal external cost are set as the baseline value in this study.

We next discuss the probability of passengers who do not want to use the taxi service to switch from taxis to private vehicles $(\pi)$. Since there are alternative mode choices for passengers when they do not want to use taxis and each mode choice has its own market share, often the outcome of the conventional mode choice model, the probability can simply be assumed to be equal to the market share for private vehicles. According to surveys in ATCI [19] and THI [20], the market share of private vehicles in Taiwan is $60.46 \%$.

Guo [21] estimated the external cost of the different modes of transportation used in Taiwan. According to Guo's study, the external cost incurred by operating a taxi is $92 \%$ of the cost of operating a private sedan and $48 \%$ of the cost of operating a motorcycle. By weighting the market share, it can be found that the external cost of operating a taxi is approximately $69 \%$ of the external cost of operating a private vehicle.

The parameters used in the numerical optimization are presented in Table 1. By substituting the settings into the optimal solution equations derived in this study, the optimization of the vacant distance, occupied distance, vacancy rate, and subsidy can be calculated.

\section{Discussion}

Table 2 presents some interesting results and implications. When externality is considered, the optimization process suggests that taxis should be used more frequently since their operation induces net external benefit when they are 
TABLE 1: Parameter and baseline values for the numerical analysis.

\begin{tabular}{|c|c|c|}
\hline Parameters & Unit & Baseline value \\
\hline Constant term of the demand function $\left(A_{1}\right)$ & - & $7.2 \times 10^{8}$ \\
\hline \multirow[t]{2}{*}{ Constant term of the waiting time function $\left(A_{2}\right)$} & - & $7.5 \times 10^{6}$ \\
\hline & & -1.4 \\
\hline \multirow[t]{2}{*}{ Price elasticity of taxi demand $\left(\alpha_{1}\right)$} & - & -1 \\
\hline & & -0.78 \\
\hline Waiting time elasticity of taxi demand $\left(\beta_{1}\right)$ & - & -0.2 \\
\hline Vacant mileage elasticity of waiting time $\left(\alpha_{2}\right)$ & - & -1 \\
\hline Maximum social willingness-to-pay $\left(P_{m}\right)$ & NTD/veh.-km & $\$ 78.38$ \\
\hline Marginal opportunity cost (c) & NTD/veh.-km & $\$ 20.416$ \\
\hline Average loaded passengers for a taxi trip $(L)$ & passengers & 1.54 \\
\hline \multirow{2}{*}{ Marginal external cost per unit distance for a private highway vehicle trip $(e)$} & \multirow{2}{*}{ NTD/person-km } & $\$ 1.7680$ \\
\hline & & $\$ 0.2779$ \\
\hline $\begin{array}{l}\text { Probability of passengers switching to private vehicles when they do not want to use } \\
\text { taxis }(\pi)\end{array}$ & $\%$ & 60.46 \\
\hline Marginal external cost multiplier for a taxi trip $(k)$ & - & 0.69 \\
\hline
\end{tabular}

TABLE 2: Optimization results.

\begin{tabular}{|c|c|c|c|c|c|c|c|c|c|}
\hline \multirow{3}{*}{ Variables } & \multicolumn{8}{|c|}{ Solutions } & \\
\hline & \multirow{2}{*}{\multicolumn{3}{|c|}{$\begin{array}{c}\text { With no consideration of } \\
\text { externality }\end{array}$}} & \multicolumn{6}{|c|}{ With the consideration of externality } \\
\hline & & & & \multicolumn{3}{|c|}{$e=0.2779$} & \multicolumn{3}{|c|}{$e=1.7680$} \\
\hline $\begin{array}{l}\text { Price elasticity of taxi } \\
\text { demand }\left(\alpha_{1}\right)\end{array}$ & -1.4 & -1 & -0.78 & -1.4 & -1 & -0.78 & -1.4 & -1 & -0.78 \\
\hline $\begin{array}{l}\text { Occupied distance }\left(O^{*}\right) \\
(\mathrm{km} / \text { day })\end{array}$ & $5,756,306$ & $22,657,728$ & $44,971,503$ & $5,780,323$ & $22,726,929$ & $45,083,479$ & $5,914,402$ & $23,113,859$ & $45,711,208$ \\
\hline $\begin{array}{l}\text { Vacant distance }\left(V^{*}\right) \\
(\mathrm{km} / \text { day })\end{array}$ & 826,300 & $3,711,662$ & $7,907,173$ & 821,311 & $3,686,661$ & $7,851,246$ & 796,573 & $3,562,023$ & $7,571,859$ \\
\hline $\begin{array}{l}\text { Total operation distance } \\
(\mathrm{km} / \text { day })\end{array}$ & $6,582,606$ & $26,369,390$ & $52,878,676$ & $6,601,634$ & $26,413,590$ & $52,934,725$ & $6,710,975$ & $26,675,882$ & $53,283,067$ \\
\hline Vacancy rate $\left(R^{*}\right)(\%)$ & 12.55 & 14.08 & 14.95 & 12.44 & 13.96 & 14.83 & 11.87 & 13.35 & 14.21 \\
\hline $\begin{array}{l}\text { Fare }\left(P^{*}\right) \\
(\mathrm{NTD} / \mathrm{veh} .-\mathrm{km})\end{array}$ & 20.416 & 20.416 & 20.416 & 20.350 & 20.350 & 20.350 & 19.994 & 19.994 & 19.994 \\
\hline $\begin{array}{l}\text { Waiting time }\left(w^{*}\right) \\
\text { (min.) }\end{array}$ & 2.141 & 2.021 & 0.949 & 9.132 & 2.034 & 0.955 & 9.415 & 2.106 & 0.991 \\
\hline $\begin{array}{l}\text { Social welfare }\left(W^{*}\right) \\
\text { (NTD/day) }\end{array}$ & $2.141 \times 10^{8}$ & $8.895 \times 10^{8}$ & $1.821 \times 10^{9}$ & $2.145 \times 10^{8}$ & $8.905 \times 10^{8}$ & $1.822 \times 10^{9}$ & $2.170 \times 10^{8}$ & $8.965 \times 10^{8}$ & $1.830 \times 10^{9}$ \\
\hline \multicolumn{10}{|l|}{$\begin{array}{l}\text { Net external benefit } \\
\text { (NTD/day) }\end{array}$} \\
\hline$e=1.7680$ & $9.467 \times 10^{6}$ & $3.726 \times 10^{7}$ & $7.396 \times 10^{7}$ & $9.506 \times 10^{6}$ & $3.738 \times 10^{7}$ & $7.414 \times 10^{7}$ & $9.727 \times 10^{6}$ & $3.801 \times 10^{7}$ & $7.518 \times 10^{7}$ \\
\hline$e=0.2779$ & $1.488 \times 10^{6}$ & $5.857 \times 10^{6}$ & $1.163 \times 10^{7}$ & $1.494 \times 10^{6}$ & $5.875 \times 10^{6}$ & $1.165 \times 10^{7}$ & $1.529 \times 10^{6}$ & $5.975 \times 10^{6}$ & $1.182 \times 10^{7}$ \\
\hline \multicolumn{10}{|l|}{$\begin{array}{l}\text { Net external benefit } \\
\text { difference }{ }^{a}(\mathrm{NTD} / \text { day })\end{array}$} \\
\hline$e=1.7680$ & 0 & 0 & 0 & $3.951 \times 10^{4}$ & $1.139 \times 10^{5}$ & $1.842 \times 10^{5}$ & $2.601 \times 10^{5}$ & $7.504 \times 10^{5}$ & $1.217 \times 10^{6}$ \\
\hline$e=0.2779$ & 0 & 0 & 0 & $6.210 \times 10^{3}$ & $1.790 \times 10^{4}$ & $2.896 \times 10^{4}$ & $4.088 \times 10^{4}$ & $1.180 \times 10^{5}$ & $1.91 \times 10^{5}$ \\
\hline $\begin{array}{l}\text { Average operation cost } \\
\text { (NTD/veh.-km) }\end{array}$ & 23.347 & 23.760 & 24.006 & 23.317 & 23.728 & 23.971 & 23.166 & 23.562 & 23.798 \\
\hline $\begin{array}{l}\text { Subsidy }\left(S^{*}\right) \\
(\mathrm{NTD} / \mathrm{km})\end{array}$ & 2.931 & 3.344 & 3.590 & 2.967 & 3.378 & 3.622 & 3.172 & 3.568 & 3.804 \\
\hline
\end{tabular}

${ }^{a}$ Compared with the corresponding net external benefit without considering externality.

occupied. Hence, with the consideration of externality, the optimal occupied distance, total operation distance, and waiting time will be higher, whereas the fare, vacant distance, and vacant rate will be lower than the optimization results when externality is not considered.
In fact, there are two kinds of force which could result in a lower vacancy rate when externality is considered. When a taxicab is occupied, the operation of the taxi will create a positive net external effect. Hence, when the externality is considered, the optimal occupied distance is lengthened; 
on the other hand, when a taxicab is vacant, the cruising behavior will have a negative net external effect so that the optimal vacant distance is shortened.

It can also be found that, in all three scenarios $\left(\alpha_{1}=\right.$ $-1.4,-1$, and -0.78$)$, as the marginal external cost increases, the occupied distance, total operation distance, subsidy, and social welfare also increase, whereas the vacant distance decreases. This result suggests that, in certain regions where higher marginal external cost of private vehicles exists (e.g., in some developing countries where lower levels of pollution prevention skills exist), more attention should be paid to encouraging the use of public transportation such as taxis to increase social welfare.

Another feature about the vacancy rate which should be noted is that the lower the fare elasticity of demand is, the higher the optimal vacancy rate will be. The lower fare elasticity of demand stands for higher dependence on taxi service. Therefore, in order to increase the social welfare, the optimization procedure would tend to increase the vacancy rate.

Regarding the fare, it can be seen that the fare decreases as the marginal external cost of operating a private vehicle increases. In the first-best environment, the social optimal fare is equal to the marginal social cost, which is the sum of the private operation cost and the external cost or the private operation cost minus the external benefit. The model in this study suggests that when the marginal external cost of private vehicle operation increases, the external benefit of the taxi business will also increase. Hence, the higher the marginal external cost, the lower the optimal fare.

Furthermore, it is also found that the subsidy should increase as the marginal external cost of private vehicle use increases and the fare elasticity of demand decreases (see Table 2). This finding is quite reasonable since lower elasticity could mean lower sensitivity. In comparison with the higher elasticity environment, more subsidies are needed in the lower elasticity environment so as to encourage the use of taxis, leading to higher occupied distance.

\section{Summary and Conclusions}

The purpose of this study was to achieve the objective of maximized welfare with willingness-to-pay taking the external effects into consideration for the cruising taxi market. The closed forms of the optimal vacancy rate, optimal fare, and optimal subsidy were also derived. The optimization results show that the optimal vacancy rate and optimal subsidy are the outcome of the functions of price elasticity, waiting time elasticity, maximum social willingness-to-pay, net marginal social external cost, and marginal private cost.

The results of numerical analysis indicate that when considering the externalities, taxis should be used more frequently, since their operation generates a net external benefit when they are occupied. Hence, the optimized occupied distance, total operation distance, and subsidy should be higher, whereas the fare, vacant distance, and vacant rate should be lower than the optimization results without the consideration of the externalities.
The results of the sensitivity analysis show that the arc elasticity of the vacant distance is 0.034 , whereas the arc elasticity of the occupied distance is 0.028 . This result suggests that both the vacant and occupied distances are relatively inelastic and the vacant distance is more sensitive to the marginal external cost than the occupied distance. Due to the low sensitivity, the estimation accuracy of the marginal external cost is less important than the optimal vacant distance, occupied distance, and vacancy rate.

However, the optimal subsidy is relatively sensitive to the marginal external cost. The sensitivity analysis shows that the average arc elasticity of the subsidy is 3.747 . The arc elasticity of the subsidy varies from 3.814 to 3.677 when $e$ changes from $-50 \%$ to $+50 \%$. This result means the optimal subsidy is relatively elastic in relation to the marginal external cost. Hence, for policy-makers, the estimation accuracy of the marginal external cost is significant when making optimal subsidy/taxation decisions. Accordingly, if the implementation of a subsidy/taxation scheme is not considered, the marginal external cost of a private trip does not have to be estimated precisely. However, if the implementation of the subsidy/taxation scheme is considered, the marginal external cost of a private trip ought to be estimated as accurately as possible in the policy-making process.

For practitioners, this study is of significance because it not only provides a supportive viewpoint on the provision of subsidies for the taxi business but also provides an estimate of the potential optimal amount of subsidy which can be treated as a valuable reference by the taxi industry.

\section{Competing Interests}

The author declares that they have no competing interests.

\section{Acknowledgments}

The author greatly appreciates the partial financial support from Ministry of Science and Technology, Taiwan, with Grant nos. MOST 104-2410-H-156-015-SSS and MOST 105-2410-H156-011.

\section{References}

[1] S. K. Chang and C.-H. Chu, "Taxi vacancy rate, fare, and subsidy with maximum social willingness-to-pay under loglinear demand function," Transportation Research Record, vol. 2111, pp. 90-99, 2009.

[2] R. Arnott, “Taxi travel should be subsidized," Journal of Urban Economics, vol. 40, no. 3, pp. 316-333, 1996.

[3] G. W. Douglas, "Price regulation and optimal service standards: the taxicab industry," Journal of Transport Economics and Policy, vol. 20, pp. 116-127, 1972.

[4] D. Ghahraman, T. Au, and D. M. B. Baumann, "Analysis of metered taxi fares," ASCE Transp Eng J, vol. 101, no. 4, pp. 807816, 1975.

[5] S. A. Ardekani, B. Jamei, and R. Herman, "A taxicab fare policy formula based on fuel consumption observation," Transportation Research Record, pp. 33-39, 1986. 
[6] S. K. Chang and B. M. Tu, "Metered taxi pricing with time-based costs," Transportation Planning Journal, vol. 23, no. 3, pp. 273288, 1994.

[7] T. S. Chang and K. Y. Sun, "A discussion of the reformation of flexible minimum fare taxi market," Urban Traffic, vol. 94, pp. 55-58, 1997.

[8] T.-H. Chang and T.-S. Chu, "Optimal taxi market control operated with a flexible initial fare policy," in Proceedings of the IEEE International Conference on Networking, Sensing and Control, vol. 2, pp. 1335-1340, Taipei, Taiwan, March 2004.

[9] R. F. Teal and M. Berglund, "The impact of taxicab deregulation in the USA," Journal of Transport Economics \& Policy, vol. 21, no. 1, pp. 37-56, 1987.

[10] M. Frankena and P. Pautler, An Economic Analysis of Taxicab Regulation, Federal Trade Commission, Washington, DC, USA, 1984.

[11] M. E. Beesley and S. Glaister, "Information for regulating: the case of taxis," The Economic Journal, vol. 93, no. 371, pp. 594615, 1983.

[12] B. Schaller, "Elasticities for taxicab fares and service availability," Transportation, vol. 26, no. 3, pp. 283-297, 1999.

[13] S. C. Wong and H. Yang, "Network model of urban taxi service: improved algorithm," Transportation Research Record, vol. 1623, pp. 27-30, 1998.

[14] H. Yang and S. C. Wong, "A network model of urban taxi services," Transportation Research Part B: Methodological, vol. 32, no. 4, pp. 235-246, 1998.

[15] K. I. Wong, S. C. Wong, and H. Yang, "Modeling urban taxi services in congested road networks with elastic demand," Transportation Research Part B: Methodological, vol. 35, no. 9, pp. 819-842, 2001.

[16] H. Yang, S. C. Wong, and K. I. Wong, "Demand-supply equilibrium of taxi services in a network under competition and regulation," Transportation Research Part B: Methodological, vol. 36, no. 9, pp. 799-819, 2002.

[17] S. K. Chang and S. M. Huang, "Optimal fare and unoccupancy rate for taxi market," Transportation Planning Journal, vol. 32, no. 2, pp. 341-363, 2003.

[18] C. H. Chu, Optimal fare and vacancy rate for a cruising taxi market [Ph.D. dissertation], Civil Engineering Department, National Taiwan University, Taipei, Taiwan, 2006.

[19] ATCI, The Survey, Calibration and Validation on Basic Data of Transportation Planning in Taipei Metropolitan, Taipei City Government, 2001.

[20] THI, "The transportation panning for Taipei metropolitan (II)," Tech. Rep., Department of Transportation, Taipei City Government, Taipei, Taiwan, 2003.

[21] Y. J. Guo, Trip costs of urban transportation [M.S. thesis], Civil Engineering Department, National Taiwan University, Taipei, Taiwan, 2002. 


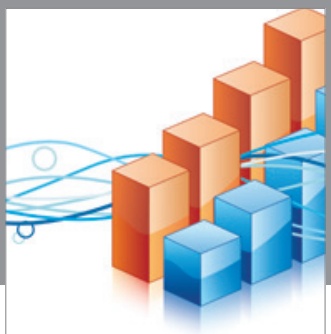

Advances in

Operations Research

vatem alat4

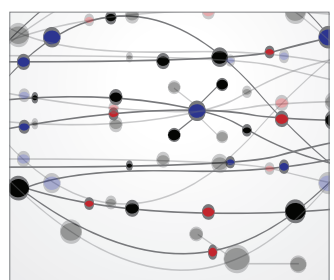

\section{The Scientific} World Journal
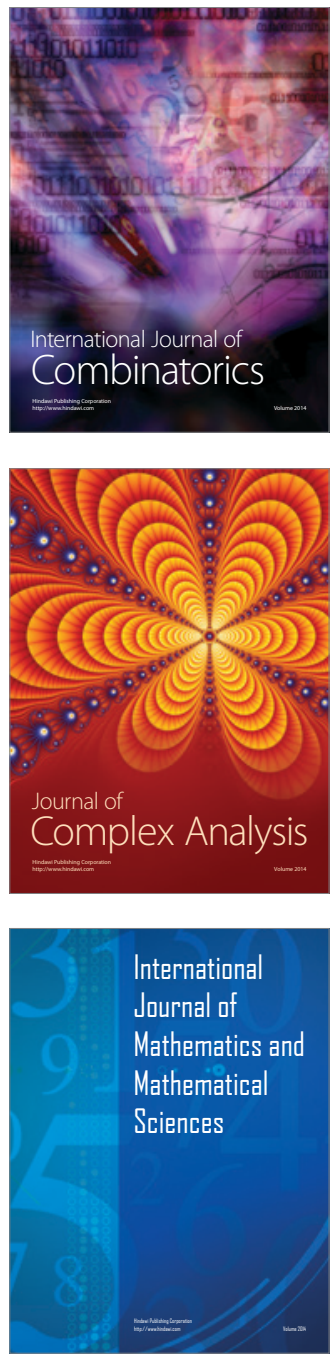
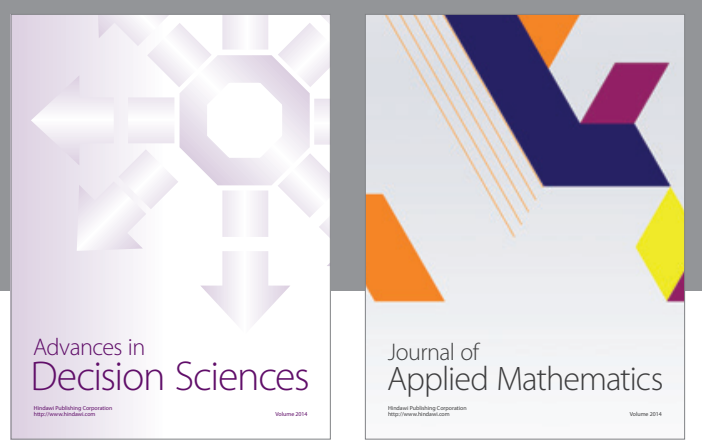

Algebra

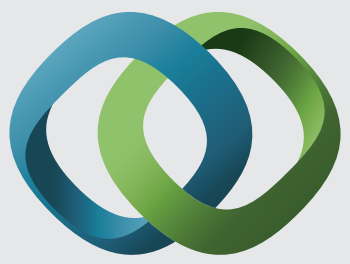

\section{Hindawi}

Submit your manuscripts at

https://www.hindawi.com
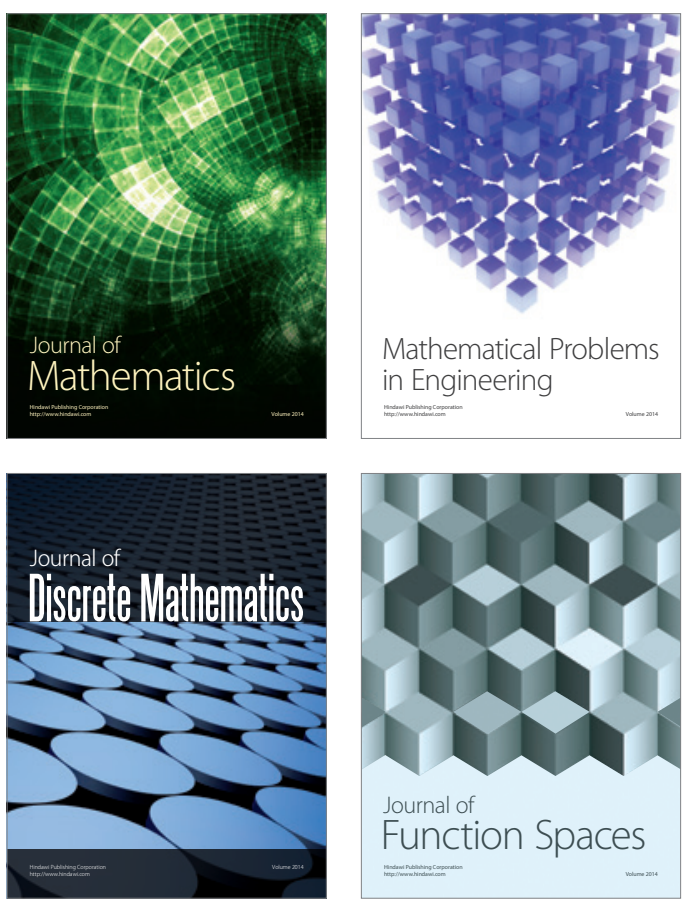

Mathematical Problems in Engineering
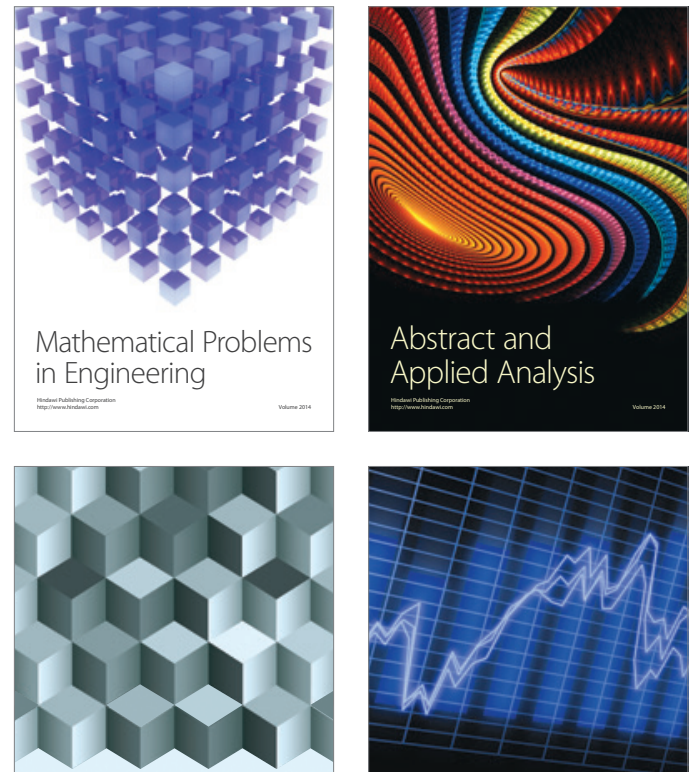

Journal of

Function Spaces

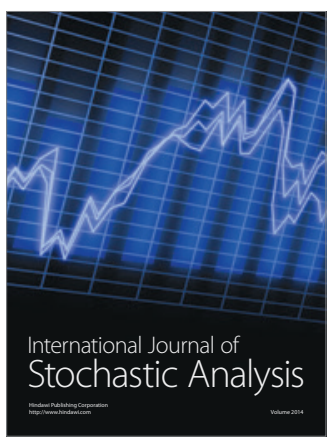

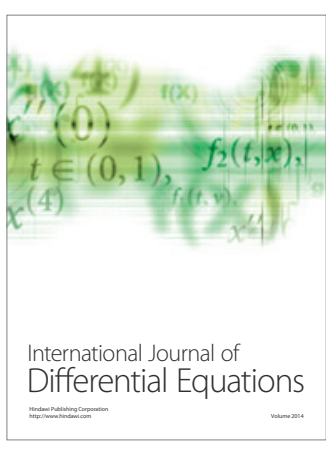
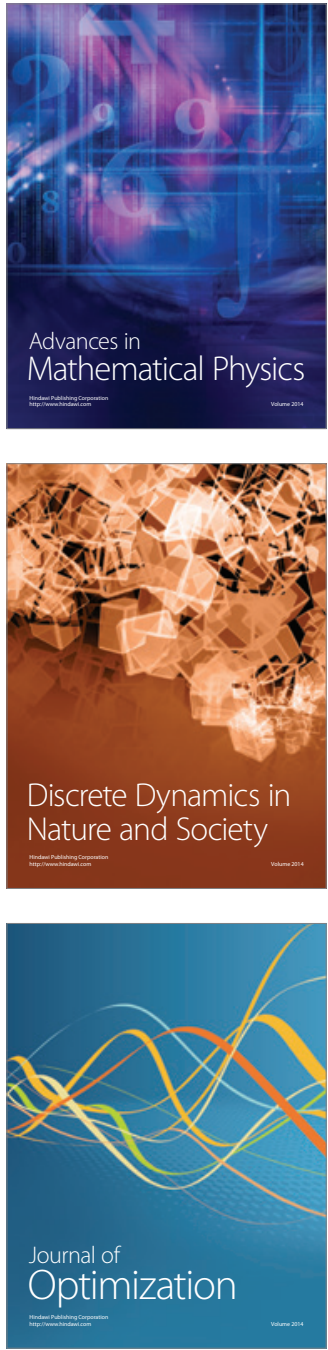